\title{
Human salivary gland stem/progenitor cells remain dormant even after irradiation
}

\author{
YUKI TATSUISHI $^{1}$, MAKOTO HIROTA ${ }^{1}$, TERUKI KISHI ${ }^{1}$, MAKOTO ADACHI ${ }^{1}$, TAKAFUMI FUKUI ${ }^{1}$, \\ KENJI MITSUDO ${ }^{1}$, SHINJIRO AOKI ${ }^{2}$, YOSHIRO MATSUI ${ }^{1}$, SUSUMU OMURA ${ }^{2}$, \\ HIDEKI TANIGUCHI $^{3}$ and IWAI TOHNAI ${ }^{1}$ \\ ${ }^{1}$ Department of Oral and Maxillofacial Surgery, Yokohama City Iniversity Graduate School of Medicine; \\ ${ }^{2}$ Department of Oral and Maxillofacial Surgery, Yokohama City University Medical Center Hospital, \\ 4-57 Urafune-chou, Minami-ku, Yokohama 232-0024; ${ }^{3}$ Regenerative Medicine, \\ Yokohama City University Graduate School of Medicine, 3-9 Fuku-ura, \\ Kanazawa-ku, Yokohama 236-0004, Japan
}

Received December 29, 2008; Accepted February 11, 2009

DOI: 10.3892/ijmm_00000240

\begin{abstract}
Progressive loss of salivary gland function occurs in most patients undergoing head and neck radiotherapy. It is unclear whether adult salivary gland tissue contains stem/ progenitor cells. In this study, we used a colony assay to clarify the presence of stem/progenitor cells in adult submandibular glands after irradiation. We developed a novel culture system that promotes single-cell colony formation with low density culture of irradiated and non-irradiated adult human submandibular gland cells using serum-free medium following serumsupplemented medium. The cells from all samples, except those obtained from the oldest patient who received the highest radiation dose, expressed acinar, ductal, and myoepithelial cell-lineage markers with reverse transcription-polymerase chain reaction (RT-PCR) and immunostaining. A sub-culture of these colonies with serum-free medium showed high multipotency. These results are the first description of presence of salivary gland stem/progenitor cells with selfrenewal, high proliferation and multipotent differentiation activity in salivary glands, even after irradiation. The survival of the cells depends on radiation dose and cell aging.
\end{abstract}

\section{Introduction}

Every year, $>45,000$ new patients are treated for head and neck cancer worldwide. Radiotherapy, either alone or in combination with surgery and chemotherapy, is often applied to treat these patients, and salivary glands are therefore at a

Correspondence to: Dr Makoto Hirota, Department of Oral and Maxillofacial Surgery, Yokohama City University Graduate School of Medicine, 3-9 Fuku-ura, Kanazawa-ku, Yokohama 236-0004, Japan

E-mail: mhirota@med.yokohama-cu.ac.jp

Key words: salivary gland stem cell, radiation injury, cell culture risk for radiation injury. Radiotherapy causes progressive loss of salivary gland functions that persists for life, leading to xerostomia, dental caries, and dysarthria. These symptoms severely limit the patient's quality of life $(1,2)$.

The management of radiation-induced xerostomia includes promoting proper oral hygiene and use of artificial saliva, lubricants, and cholinergic agonists to stimulate salivary gland function. Since radiation-induced salivary gland dysfunction is irreversible, treatment methods for regeneration of salivary glands and physiological secretion of saliva from reconstituted glands are needed.

Stem cells have self-renewal and multilineage differentiation potential (3), and their progeny, progenitor cells, have multiple differentiation abilities but cannot self-renew. In recent years, stem cell research has advanced remarkably and shown that stem cells are present in most adult tissues and are responsible for their renewal and repair $(4,5)$. These cells are present not only in relatively simple tissues, but also in exocrine glands, such as mammary glands (6-9). Other studies indicated the presence of salivary gland stem/progenitor cells in rodents $(10,11)$ and humans $(12-14)$. Using a low-density culture, Kishi et al (15) reported multipotent salivary gland stem/ progenitor cells that differentiated to form salivary gland cells.

Some clinical reports showed that patients who experienced xerostomia one year after irradiation subsequently recovered some salivary function. This recovery was associated with the radiation dose $(16,17)$, suggesting the existence of regenerative stem cells in irradiated salivary glands.

The stem-cell colony assay was developed using hematopoietic stem cells that form colonies consisting of various blood cells in a soft agar medium (18). By identifying clonal colonies consisting of different types of blood cells formed from a single hematopoietic stem cell, the presence of proliferative, multipotent stem/progenitor cells are demonstrated. Development of a culture system of clonal colonies of salivary gland cells obtained from clinical samples enables us to confirm the presence of human salivary gland stem/progenitor cells.

In this study, to isolate and characterize salivary gland stem/progenitor cells, we developed a colony assay for human 
salivary gland cells obtained from clinical samples. In addition, we used the assay to investigate the presence of salivary gland stem/progenitor cells following irradiation.

\section{Materials and methods}

Tissue samples and histology of the submandibular gland. Salivary gland cell samples were obtained from patients with head and neck cancer who had undergone resection of lingual and submandibular salivary glands. The cancers were not salivary gland tumors. Submandibular glands from patients who received preoperative therapeutic irradiation were also used in this study. We used one non-irradiated (sample 1, 66-year-old man) and three irradiated (sample 2, 55-year-old woman; sample 3, 39-year-old man; and sample 4, 75-year-old man) submandibular gland tissue samples. The irradiation doses for samples 2 and 3 were $40 \mathrm{~Gy}$, and sample 4 was $60 \mathrm{~Gy}$. Non-irradiated lingual gland tissue was used as a positive control for reverse transcription-polymerase chain reaction (RT-PCR) analysis and immunostaining of cultured submandibular cells. All patients provided informed consent for this study, which was approved by the Ethics Committee of Yokohama City University Graduate School of Medicine. All patients were negative for hepatitis $B$ and $C$ viruses, human immunodeficiency virus, and adult T-cell leukemia-associated antigen.

Histological findings of the non-irradiated and irradiated submandibular gland samples were observed after hematoxylineosin (H-E) staining.

Dissociation of submandibular gland cells. The salivary gland tissues were carefully minced with a razor blade and placed in $0.05 \%$ trypsin-ethylenediaminetetraacetic acid (EDTA) (Gibco BRL/Invitrogen, Carlsbad, CA, USA) containing $0.07 \%$ collagenase (Nitta Gelatin, Osaka, Japan), incubated at $37^{\circ} \mathrm{C}$ for $90 \mathrm{~min}$, centrifuged at $300 \mathrm{x} \mathrm{g}$, and filtered through a Millipore filter (pore size, $20 \mu \mathrm{m}$ ). Cell viability exceeded $85 \%$ as assessed by trypan blue dye exclusion.

In vitro colony formation. Cells were placed in 35-mm culture dishes (CellStar ${ }^{\circledR}$, Greiner Bio-One, Frickenhausen, Germany) at a density of 300 cells $/ \mathrm{cm}^{2}$ and cultured in a primary medium for two days. Our standard primary medium is a 1:1 mixture of Dulbecco's modified Eagle's medium and F-12 (Sigma Chemical, St. Louis, MO, USA) with 10\% fetal bovine serum (FBS; Morgate Biotech Bulimba, Queensland, Australia), $\gamma$-insulin (1 mg/ml) (Wako, Tokyo, Japan), dexamethasone $\left(1 \times 10^{-7} \mathrm{~mol} / \mathrm{l}\right)$, nicotinamide (10 mmol/l) (Sigma), L-glutamine (2 mmol/l) (Gibco), B-mercaptoethanol (50 mmol/l) (Sigma), HEPES (5 mmol/l) (Wako), and penicillinstreptomycin (Gibco). After 2 days of culture, the medium was changed to serum-free Cnt-24 medium (progenitor cell-targeted oral epithelium medium) (CELLmTEC Advanced Cell Systems, Bern, Switzerland). During the culture period, cells were incubated at $37^{\circ} \mathrm{C}$ in a humidified atmosphere of $5 \%$ $\mathrm{CO}_{2}$, and the medium was changed every 4 days.

RT-PCR analysis. A cloning ring (Iwaki Glass, Tokyo, Japan) was placed on the colony and total RNA was prepared using the Qiagen micro kit (Qiagen GmbH, Hilden, Germany).
Before reverse transcription (RT), $0.8 \mu \mathrm{l}$ of oligo (dt) primers were added to total RNA solution. The reaction mixture was heated at $75^{\circ} \mathrm{C}$ for $5 \mathrm{~min}$ and hybridized at $42^{\circ} \mathrm{C}$ for $5 \mathrm{~min}$. cDNA was synthesized from total RNA in $20 \mu \mathrm{l}$ of reaction mixture containing $5 \mathrm{x}$ first strand buffer, $0.5 \mathrm{mmol} / \mathrm{l} \mathrm{dNTP}$ and $200 \mathrm{U}$ of Super Script III (Invitrogen). The polymerase chain reaction (PCR) was conducted using 10x Ex Taq Buffer, dNTP mixture, and Ex Taq DNA polymerase, with the total reaction volume being $20 \mu \mathrm{l}$ (Takara, Tokyo, Japan). The human salivary gland specific primers were, amylase (Amy) (5'-TTG TCG TCT GTC TGG TCT TCT C-3' and 5'-AGC AAG CAT AAA TCC AAC TGC-3'), aquaporin3 (AQP3) (5'-CCT GGT GAT GTT TGG CTG T-3' and 5'-ACA CGA TAA GGG AGG CTG TG-3'), $\mathrm{Na}^{+} / \mathrm{K}^{+}$ATPase (5'-TCC TGA AGG GTT CCA GTT TG-3' and 5'-AGT CAT TCA CAC CGT CAC CA-3'), cytokeratin 7 (CK7) (5'-CAG GAT GTG GTG GAG GAC TT-3' and 5'-AAC TTG GCA CGC TGG TTC T-3'), cytokeratin 14 (CK14) (5'-GGC CTG TCT GTC TCA TCC TC-3' and 5'-GGC TCT CAA TCT GCA TCT CC-3'), cytokeratin 18 (CK18) (5'-GGA GCA CTT GGA GAG AAG G-3' and 5'-TGG CAA TCT GGG CTT GTA G-3'), $\alpha$-smooth muscle actin ( $\alpha$-SMA) (5'-GTG ACG AAG CAC AGA GCA AA-3' and 5'-GAT GAA GGA TGG CTG GAA CA-3'), vimentin (Vim) (5'-TCA GAG AGA GGA AGC CGA AA-3' and 5'-GCT TCA ACG GCA AAG TTC TC-3'), and GAPDH (5'-CTC TGC TCC TCC TGT TCG AC-3' and 5'-TTG ATT TTG GAG GGA TCT CG-3'). PCR cycles were as follows, initial denaturation at $94^{\circ} \mathrm{C}$ for $5 \mathrm{~min}$, followed by 35 cycles of $94^{\circ} \mathrm{C}$ for $40 \mathrm{sec}, 58-60^{\circ} \mathrm{C}$ for $40 \mathrm{sec}$ (annealing), $72^{\circ} \mathrm{C}$ for $40 \mathrm{sec}$, and final extension at $72^{\circ} \mathrm{C}$ for $7 \mathrm{~min}$. PCR products were separated on $1.5 \%$ agarose gels.

Immunohistochemistry and immunocytochemistry. Salivary gland tissues were fixed in $2 \%$ paraformaldehyde for $2 \mathrm{~h}$ and dehydrated with $30 \%$ sucrose for $6 \mathrm{~h}$. The tissues were frozen and $5-\mu \mathrm{m}$ thick frozen sections were prepared and washed with TBS-Ca. Cultured cells from each colony were washed three times with PBS, fixed with methanol at $-30^{\circ} \mathrm{C}$ for $10 \mathrm{~min}$, and washed in PBS including $0.05 \%$ polyoxyethylene 20 sorbitan monolaurate (Tween-20) (Wako). Non-specific binding was blocked with Block Ace (Dainippon Seiyaku, Osaka, Japan). The fixed sections and cells were incubated with primary antibodies for human cytokeratin, cytokeratin 7 (Dako Cytomation, Golstrup, Denmark), cytokeratin 14 (Abcam, Cambridge, UK), amylase (Sigma), aquaporin 3 (Chemicon, Temecula, CA, USA), and SMA (Lab Vision, CA, USA) in a moist chamber for $16 \mathrm{~h}$ at $4^{\circ} \mathrm{C}$. The fixed sections and cells were washed in PBSTween-20, blocked, and incubated with Alexa 488-conjugated donkey anti-rabbit IgG (Molecular Probes, Eugene, OR, USA) and $\mathrm{Cy} 3$-conjugated donkey anti-mouse IgG (Jackson ImmunoResearch, Inc., West Grove, PA, USA) for $1 \mathrm{~h}$ at room temperature. After a final wash, the cells were viewed using a Zeiss Axio Imager M1 (Zeiss, Oberkochen, Germany).

Replating of colony. A cloning ring was placed on the colony, $0.05 \%$ trypsin EDTA (Gibco) was placed inside the ring, and the colony and ring were incubated at $37^{\circ} \mathrm{C}$ for $10 \mathrm{~min}$. Once the cells were floating, they were collected and added to 24-well culture plates $\left(\right.$ CellStar $^{\circledR}$, Grenier Bio-One, Charlotte, NC, USA). 

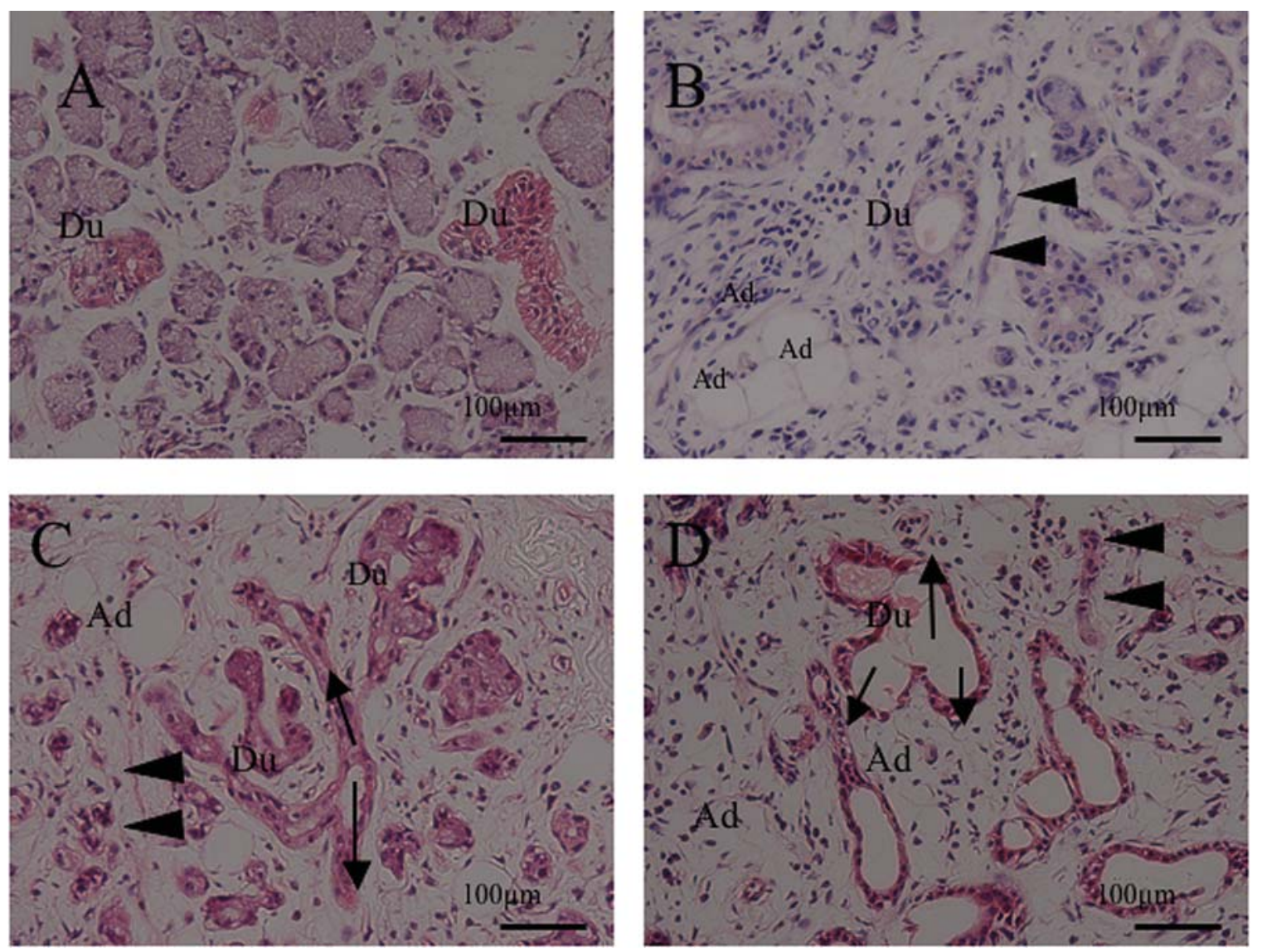

Figure 1. Hematoxylin-eosin stained submandibular salivary gland cells from clinical samples. Sample 1 (A) was obtained from a patient who did not undergo radiation for neck tumors. Samples 2 (B), 3 (C), and 4 (D) were obtained from patients who underwent radiation and chemotherapy before surgery for neck tumors. The acinar cells are collapsed in B-D and are replaced by adipose tissue (Ad) and fibrous tissue (arrowheads). Ductal structures are expanded in an irradiated salivary gland (arrows).

\section{Results}

$H$-E staining of the clinical samples. H-E staining of the samples is shown in Fig. 1. Sample 1 was obtained from a patient who had no history of radiation therapy (Fig. 1A). Samples 2-4 were obtained from patients who underwent radiation and chemotherapy prior to neck surgery. The acinar cells were collapsed in samples 2-4 and replaced by adipose and fibrous tissues, while ductal structures were expanded in the irradiated salivary gland (Fig. 1B-D). In particular, the salivary gland structure in sample 4 was almost destroyed (Fig. 1D).

Colony formation of submandibular gland cells. Submandibular gland cells were first dissociated, seeded at 300 cells $/ \mathrm{cm}^{2}$ in a $35-\mathrm{mm}$ culture dish, and cultured in a 10\% FBS-DMEM/F12 for 2 days. The medium was then exchanged for serum-free Cnt-24 medium, and the cells adhered to the dish after 2 further days. By day 14 they had grown into large colonies (Fig. 2A-D).

Colony-forming assay of cells isolated from the submandibular gland tissue. Colony counts were performed on days 3, 7, and 14 of culture. We were able to culture cells obtained from samples 1-3 (Pt. 1, 2, and 3), but not from sample 4. On culture day 3 , the frequency of colony formation in the irradiated submandibular gland cells was higher than that of the non-irradiated cells, but it was lower on culture day 7. All samples showed an approximately equivalent frequency of colony formation on culture day 14 (Fig. 2E).

Immunocytochemical analysis of cell-lineage marker expression in clonal colonies. The expression of salivary-gland cell-lineage markers in sample tissues and culture colonies is shown in Fig. 3. Photographs were taken on days 3 (Fig. 3G, I and $\mathrm{K}$ ) and 7 (Fig. 3H, J, and L). On day 3, the only markers expressed were specific for ductal and epithelial cells. On day 7 , the markers for amylase, aquaporin 3, and SMA were also expressed (Fig. 3).

Expression of cell-lineage marker genes in clonal colonies. Expression of cell-lineage marker genes is shown in Fig. 4. The RT-PCR analysis was performed on the colonies from the non-irradiated (sample 1) and irradiated submandibular glands (samples 2 and 3) after 14 days of culture. Five of the nine colonies obtained from the non-irradiated sample expressed acinar, ductal, and myoepithelial cell-lineage markers, whereas colonies obtained from the irradiated samples tended to express fewer lineage markers.

Replating of colony for subculture. When colonies were transferred using a cloning ring with Cnt-24 medium, six of the nine colonies from patient 3 showed high multipotency (data not shown). 

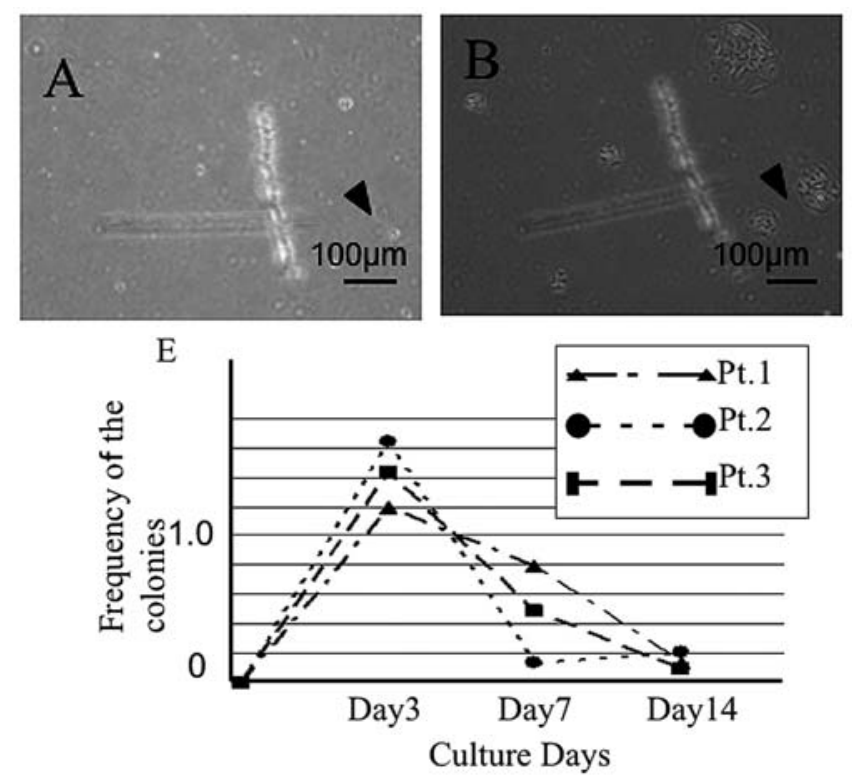

\section{Discussion}

To our knowledge, this is the first description of isolation of salivary gland stem/progenitor cells from irradiated salivary glands. Our first aim was to establish the cell preparation and
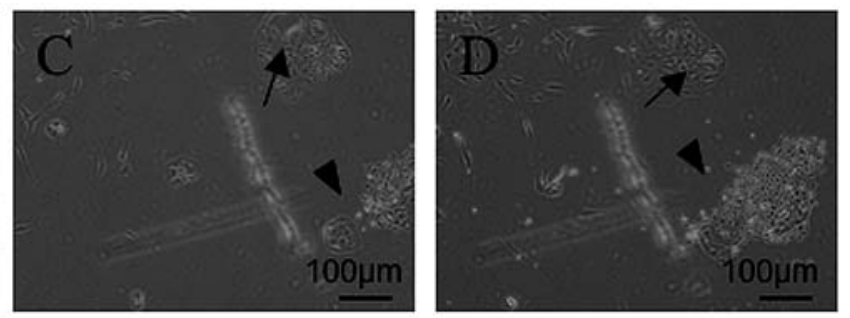

Figure 2. Colony formation of cells obtained from submandibular salivary gland clinical samples (A-D). Submandibular gland cells were dissociated, seeded at 300 cells $/ \mathrm{cm}^{2}$ in a $35-\mathrm{mm}$ culture dish, and cultured in DMEM/F12 with $10 \%$ FBS for 2 days. The medium was changed to serum-free Cnt-24 medium. Cells adhered to the dish after 2 days (A) and grew into larger colonies by day 3 (B), 7 (C), and 14 (D) (arrowheads). (E) Colony-forming assay of cells isolated from submandibular salivary gland tissue. Pt. 1, 2, and 3 indicate samples 1,2 , and 3 , respectively. Colony counts were performed on days 3,7 , and 14 of culture.

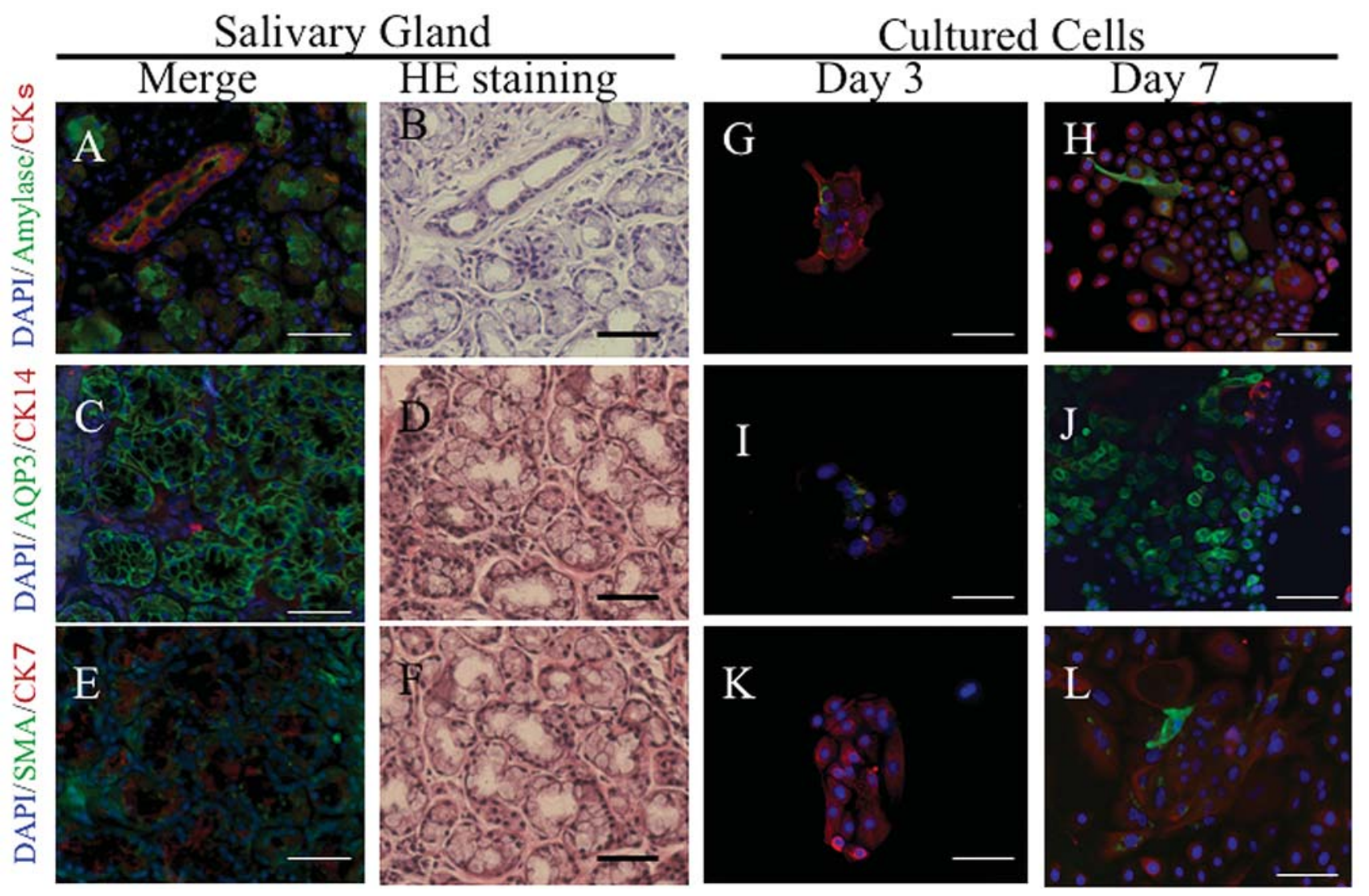

Figure 3. Expression of cell-lineage markers in salivary gland tissue from clinical samples (A-F) and colonies (G-L). Lingual gland tissue obtained from a 20year-old man was used as a positive control. Double immunostaining was performed for the acinar cell-specific marker amylase and the epithelial cell-specific marker CKs (A, B, G, and H); the acinar cell-specific marker aquaporin 3 and the ductal cell-specific marker cytokeratin 14 (C, D, I, and J); and the ductal cell-specific marker cytokeratin 7 and the myoepithelial cell-specific marker $\alpha$-smooth-muscle actin (SMA) (E, F, K, and L). The photographs of the colonies were taken on day $3(\mathrm{G}, \mathrm{I}$, and $\mathrm{K})$ and on day $7(\mathrm{H}, \mathrm{J}$, and $\mathrm{L})$. Only markers specific for ductal and epithelial cells were expressed on day 3. On day 7, the acinar and myoepithelial cell-specific markers amylase, aquaporin 3, and SMA were expressed along with the ductal cell-specific markers. 
$300 \mathrm{cells} / \mathrm{cm}^{2}$ cultured for 14Days

\section{Submandibular Gland Irradiated Submandibular Gland}

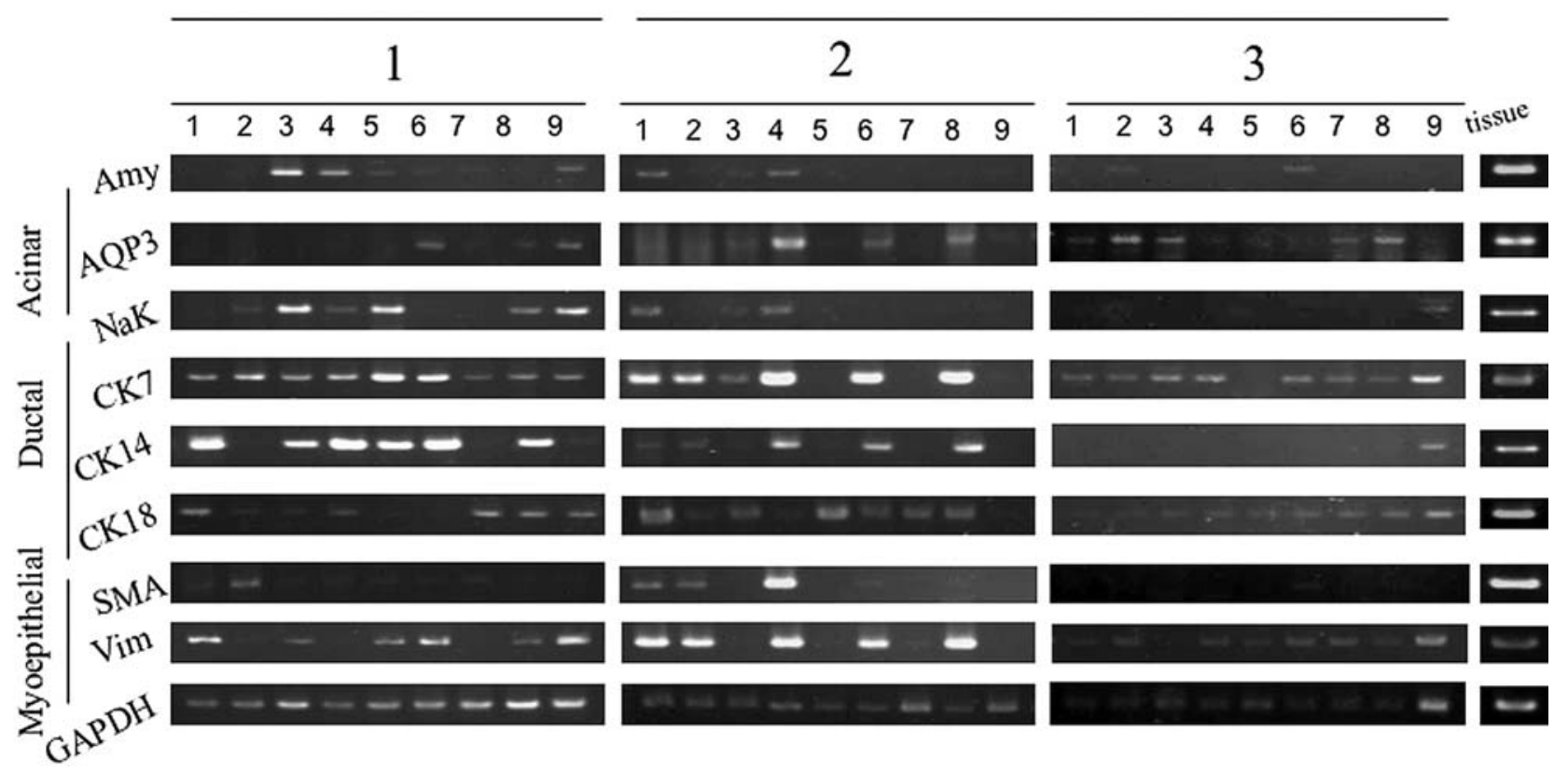

Figure 4. Expression of cell-lineage marker genes. RT-PCR was conducted for colonies obtained from the clinical salivary gland samples after 14 days of culture. The samples were obtained from a non-irradiated submandibular gland (no. 1), and two irradiated submandibular glands (nos. 2 and 3 ). Five of the nine colonies obtained from the non-irradiated submandibular glands expressed three different cell-lineage markers. Colonies obtained from the irradiated submandibular glands tended to express fewer cell-lineage markers than those obtained from non-irradiated submandibular glands.

but a method that would enable low-density culture of salivary gland cells is not yet established. Firstly, in a pilot study aimed at establishing culture conditions, we tried to culture the cells using only serum-free or -containing media. However, culture was not possible in either method. We succeeded in culturing human salivary gland cells at a low density $\left(300\right.$ cells $\left./ \mathrm{cm}^{2}\right)$ using DMEM/F12 with 10\% FBS for the first 2 days followed by serum-free Cnt-24 media. Because of the time lapsed since clinical samples were obtained, we used epidermal growth factor (EGF) and fibroblast growth factor (FGF) in both serum-free and -supplemented medium. We believe that the addition of these growth factors to the Cnt-24 promoted cell differentiation of the salivary gland stem/progenitor cells, whereas that in the serum-supplemented medium was effective for cell proliferation.

In this study, we cultured cells obtained from four clinical submandibular gland samples. Using the culture conditions mentioned above, we observed colony formation in the nonirradiated sample and in two of the three samples from irradiated submandibular glands (samples 2 and 3). As shown in Fig. 1, the irradiated submandibular glands showed tissue damage. In particular, the radiation-induced tissue injury in sample 4 was so severe that the cells did not form colonies, indicating that a high radiation dose and aging prevented colony formation. However, during the first few days of culture, there was higher proliferation activity in the colonyforming irradiated cells compared with the colony-forming non-irradiated cells. This trend reversed by culture day 7 , and the non-irradiated cells showed higher proliferation activity than the irradiated cells, suggesting that the stem/progenitor cells were tolerant of radiation. It is also possible that stem/ progenitor cell density was relatively higher in the irradiated samples following cell dissociation and culture. The irradiated cells formed more colonies than did non-irradiated cells on culture day 3 , but by culture day 7 , the frequency of colony formation from irradiated cells was less than that of the nonirradiated samples. On culture day 14, all samples showed approximately the same number of colonies. Cells from all samples were similarly well differentiated into acinar, ductal, and myoepithelial cells. Cells from sample 4, which came from the oldest patient and received the highest radiation dose, could not be cultured, indicating that there was no difference in the absolute number of salivary stem/progenitor cells between the non-irradiated and irradiated samples, but that the stem/progenitor cells failed to survive at a threshold radiation dose. The age of this patient was also thought to be an important factor, adversely affecting cell survival.

We transferred the colonies to 24 -well plates using a cloning ring to investigate whether these colonies had the ability to self-renew, an important characteristic of stem cells. Using the Cnt-24 medium, six of the nine colonies from patient 3 showed high multipotency (data not shown), suggesting that cells cultured in this system have self-renewal ability. However, further investigation is necessary to verify this finding.

The results of this study suggest that salivary gland stem/ progenitor cells are present in clinical samples even after irradiation, when tissue damage is not severe. Some experiments on rats indicated that transplanted and cultured salivary epithelial cells regenerate submandibular glands (21). More recently, potential mesenchymal stem cells were reported to regenerate salivary glands in radiation-damage $(22,23)$. Isolation and characterization of salivary gland stem/progenitor 
cells was also reported (24). If a method is established to isolate salivary gland stem/progenitor cells, then autologous salivary gland stem/progenitor cell transplantation into atrophic or damaged glands is a basic treatment for patients with xerostomia in the future.

\section{Acknowledgements}

This study was supported in part by a Grant-in-Aid for Scientific Research (C) (No. 19592306) from Japan Society for the Promotion of Science.

\section{References}

1. Vissink A, Burlage FR, Spijkervet FKL, Jansma J and Coppes RP: Prevention and treatment of the consequences of head and neck radiotherapy. Crit Rev Oral Biol Med 14: 213-225, 2003.

2. Vissink A, Jansma J, Spijkervet FKL, Burlage FR and Coppes RP: Oral Sequelae of head and neck radiotherapy. Crit Rev Oral Biol Med 14: 199-212, 2003.

3. Slack JMW: Stem cells in epithelial tissues. Science 287: 1431-1433, 2000.

4. Potten CS, Booth C and Hargreaves D: The small intestine as a model for evaluating adult tissue stem cell drug targets. Cell Prolif 36: 115-129, 2003.

5. Potten CS, Booth C, Tudor GL, et al: Identification of a putative intestinal stem cell and early lineage marker: Musashi-1. Differentiation 71: 28-41, 2003.

6. Shackleton M, Vaillant F, Simpson KJ, et al: Generation of a functional mammary gland from a single stem cell. Nature 439: 84-88, 2006.

7. Stingl J, Eirew P, Ricketson I, et al: Purification and unique properties of mammary epithelial stem cells. Nature 439: 993-997, 2006.

8. Kordon EC and Smith GH: An entire function mammary gland may comprise the progeny from a single cell. Development 125: 1921-1930, 1998.

9. Dontu G, Abdallah WM, Wicha MS, et al: In vitro propagation and transcriptional profiling of human mammary stem/progenitor cells. Genes Dev 17: 1253-1270, 2003.

10. Kimoto M, Yura Y, Kishino M, Toyosawa S and Ogawa Y: Label-retaining cells in the rat submandibular gland. J Histochem Cytochem 56: 15-24.

11. Hisatomi Y, Okumura K, Endo F, et al: Flow cytometric isolation of endodermal progenitors from mouse salivary land differentiate into hepatic and pancreatic lineages. Hepatology 39: 667-675.
12. Rotter N, Oder J, Schlenke P, et al: Isolation and characterization of adult stem cells from human salivary gland. Stem Cells Dev 17: 509-518, 2008

13. Tran SD, Wang J, Bandyopadhyay BC, et al: Primary culture of poralized human salivary epithelial cells for use in developing an artificial salivary gland. Tissue Eng 11: 172-181, 2005.

14. Sato A, Okumura K, Matsumoto S, et al: Isolation, tissue localization, and cellular characterization of progenitors derived from adult human salivary glands. Cloning Stem Cells 9: 191-205, 2007.

15. Kishi T, Takao T, Fujita K and Taniguchi H: Clonal proliferation of multipotent stem/progenitor cells in the neonatal and adult salivary glands. Biochem Biophis Res Commun 340: 544-551, 2006.

16. Kaneko M, Shirato H, Nishioka T, et al: Scintigraphic evaluation of long-term salivary function after bilateral whole parotid gland irradiation in radiotherapy for head and neck tumor. Oral Oncol 34: 140-146, 1998.

17. Kinch CAM, Kim HM, Vineberg KA, Ship JA and Eisbruch A: Dose-effect relationship for the submanbibular salivary glands and implications for their spaing by intensity modulated radiotherapy. Int J Rad Oncol Biol Phys 72: 373-382, 2008.

18. Dicke KA, Platenburg MG and van Belkkum DW: Colony formation in agar: in vitro assay for hematopoietic stem cells. Cell Tissue Kinet 4: 463-477, 1971.

19. Okura M, Shirasuna K, Hiranuma T, Yoshioka H, Nakahara H, Aikawa T and Matsuya T: Characterization of growth and differentiation of normal human submandibular gland epithelial cells in a serum-free medium. Differentiation 54: 143-153, 1993.

20. Chopra DP and Xue-Hu IC: Secretion of $\alpha$-amylase in human parotid gland epithelial cell culture. J Cell Physiol 155: 223-233, 1993.

21. Sugito T, Kagami H, Hata K, Nishiguchi H and Ueda M: Transplantation of cultured salivary gland cells into an atrophic salivary gland. Cell Transplant 138: 691-699, 2004.

22. Lombaert IM, Wierenga PK, Kok T, Kampinga HM, de Haan G and Coppes RP: Mobilization of bone marrow stem cells by granulocyte colony-stimulating factor ameliorates radiationinduced damage to salivary glands. Clin Cancer Res 12: 1804-1812, 2006.

23. Lombaert IM, Brunsting JF, Wierenga PK, et al: Rescue of salivary gland funcion after stem cell transplantation in irradiated glands. PLoS ONE 3: E2063, 2007.

24. Kagami H, Wang S and Hai B: Restoring the function of salivary glands. Oral Dis 14: 15-24, 2008. 